\title{
Neurobiology
}

\section{What cloned genes can tell us about nerve growth factor}

\section{from Ralph A. Bradshaw}

IN the more than three decades since its discovery ${ }^{1}$, nerve growth factor (NGF) has proved to be an uncommonly valuable source of insight into the developmental biology of the peripheral nervous system in particular ${ }^{2}$, and growth regulatory molecules in general. It has provided an important pharmacological tool in immunosympathectomy ${ }^{3}$ through the early administration of anti-NGF antibodies; and it has been instrumental in establishing the importance of other polypeptide growth factors ${ }^{4}-$ indeed, epidermal growth factor was first discovered by Cohen ${ }^{5}$ during his attempts to isolate NGF, and Hendry's discovery of the uptake of NGF by nerve endings ${ }^{6}$ presaged the establishment of receptor-mediated endocytosis of other growth factors and related substances. It has also served to stimulate research on other neurotrophic factors with peripheral and central actions and which may be important in the treatment of neurological disorders ${ }^{7}$. It is therefore paradoxical that the evidence for the actions of NGF, and even its presence, has remained for more than 30 years largely circumstantial. Thus the cloning of the NGF gene by two independent groups 8.9 has now made possible for the first time a direct approach to these and other questions.

Both groups made use of the known amino acid sequence of the active $\beta$ subunit ${ }^{10}$ of mouse NGF to prepare oligonucleotide primers which identified NGF cDNA in libraries prepared from messenger RNA from mouse submandibular gland - until now the only source of substantial quantities of NGF, for reasons that remain mysterious. The cDNA sequence determined by both groups ${ }^{8,9}$ predicts exactly the same protein sequence, including an aspartic acid assignment for an undoubtedly incorrectly assigned amide in the amino acid sequence of the mature protein ${ }^{11}$. There is however some doubt about the size of the precursor protein, which contains an extremely long leader sequence that is cleaved from the $\beta$ NGF sequence to give the mature peptide. The cDNA sequence predicts three potential initiator methionine positions, occurring at positions $-187,-121$ and -119 , where the first residue of the mature protein is numbered 1. Scott et al. ${ }^{8}$ selected the methionine at position -187 , predicting a precursor protein of some 33,000 molecular weight, in agreement with a previous study ${ }^{12}$, whereas Ullrich et al. ${ }^{9}$ have selected position -121 as the actual initiation site. Their argument is largely based on the hydrophobic character of the ensuing residues which is more consistent with the known structure of other leader sequences.

Meanwhile, Ullich et al. ${ }^{9}$ have gone on to isolate the genomic DNA encoding the human NGF gene, whose structure has also more recently been determined by the Rutter group ${ }^{12}$. According to the predicted amino acid sequence, the human protein is quite similar to those of the other higher vertebrates ${ }^{13-15}$. The human genomic data also reveal only one gene copy for human NGF and allow comparison of the location of introns and exons with the putatively homologous genes of the insulin family ${ }^{16}$. In fact, the human genomic structure shows an intervening sequence of 6.6 kilobases just upstream from the initiation site suggested at position -121 . If the initiation site at -187 is the correct one, then the intron would occur in the $5^{\prime}$ precursor segment. As noted by Ullich et al. ${ }^{9}$, one rat insulin gene ${ }^{17}$ shows an intron in the corresponding position, though this feature is really not distinctive enough to be taken as strong support for a close relationship with insulin. Further evidence from other gene structures or three-dimensional analyses ${ }^{18}$ of the mature protein may be helpful.

A major issue in the processing of the $\beta$ NGF precurser is clearly resolved by these studies ${ }^{8,9}$. It has been suggested ${ }^{10}$ that the $\gamma$ subunit, an arginine-specific protease of the serine family that is normally found associated with $\beta$-NGF in the mouse submandibular gland, acts on $\beta$ precursor molecules to remove a carboxyl-terminal fragment; and indeed Berger and Shooter ${ }^{19}$ identified a precursor of the predicted molecular weight if processing were to occur at the double basic sequence found at positions -73 and $\mathbf{- 7 2}$. However, the DNA sequences show that this segment occurs not at the carboxyl but at the amino terminal of the mature protein, with only a dipeptide extending beyond the $\mathrm{C}$-terminal arginine of the mature $\beta$-NGF sequence. Although the $\gamma$ subunit may act at other poly-basic sites in the proposed precursor sequence ${ }^{9}$, it seems equally likely that the subunit is not the major processing enzyme of $\beta$ precursors. This conclusion is reinforced by the observation $s^{20}$ that guinea pig prostate is totally devoid of $y$ protein and mRNA despite the fact that it contains high concentrations of mature $\beta$-NGF ${ }^{14}$.

The CDNA probes of both the mouse and human molecules should also prove invaluable in resolving other major questions regarding the biosynthesis and action of this hormone. Since it was first observed nearly 10 years ago that NGF was specifically taken up at the presynaptic membrane of responsive neurones and retrogradely transported to the cell body 5 , it has been widely speculated that the physiologically relevant sites of synthesis of the hormone are the cells innervated by these neurones. This idea has received such enthusiastic endorsement that it now represents the basic model, not only for NGF function but also for other neuronotrophic factors, some of which have not even been purified, even though the evidence is largely circumstantial. With the availability of the cDNA probes to $\beta$ NGF, it will now be possible to test whether these neuronal end organs are, in fact, producing NGF. The probes can further establish whether NGF is present in the central nervous system. Many observations have suggested possible actions of NGF in the brain but there is little evidence that the hormone is actually found there.

It follows that the cDNA probes should be very useful in elucidating the possible role of NGF in neurological diseases. Changes in NGF concentrations have been found in many pathological conditions ${ }^{21}$ but there is no definitive evidence linking them with the disease. However, observations such as reported by Bell et al. ${ }^{22}$ that deprivation of NGF through transferred immunity can produce a condition similar to that found in familial dysautonomia are highly suggestive. The long-awaited cloning of the $\beta$-NGF gene will not only provide a tool for investigating the nature of these neurological diseases, but could clearly also lead to the production of the human $\beta$. NGF protein in quantities large enough to be therapeutically useful.

Ralph A. Bradshaw is Professor and Chairman of the Department of Biological Chemistry, California College of Medicine, University of California, Irvine, California 92717.

1. Levi-Montalcini, R. \& Hamburger, v. J. exp. Zool. 116 321 (1951).

2. Levi-Montalcini, R. \& Angeletti, P.U. Physiol. Rev. 48, 534 (1968).

3. Steiner, G. \& Schonbaum, E. (eds) Immunosympathectomy (Elsevier, Amsterdam, 1972).

4. Bradshaw, R.A. \& Rubin, J.S. J. supramolec. Struct. 14, 183 (1980).

5. Cohen, S. J. biol. Chem. 237, 1555 (1962).

6. Hendry, I.A. et al. Brain Res. 68, 103 (1974).

7. Perez-Polo, J.R. \& de Vellis, J. J. Neurosci. Res. 8, 127 (1982).

8. Scott, J. et al. Nature 302, 538 (1962)

9. Ullich, A., Gray, A., Berman, C. \& Dull, T.J. Nature 303, 821 (1983).

10. Angeletti, R.H. \& Bradshaw, R.A. Proc, natn. Acad. Sci. U.S.A. 68, 2417 (1971).

11. Angeletti, R.H., Hermodson, M.A. \& Bradshaw, R.A. Biochemistry 12, 100 (1973).

12. Selby, M., Scott, J. \& Rutter, W.J. Personal communication.

13. Harper, G.P., Glanville, R.W. \& Thoenen, H. J. biol. Chem. 257, 8541 (1982).

14. Rubin, J.S. \& Bradshaw, R.A. J. Neurosci. Res. 6, 451 (1981).

15. Hogue-Angeletti, R.A., Frazier, W.A., Jacobs, J.W. Niall, H.D. \& Bradshaw, R.A. Biochemistry 15, 26 (1976).

16. Frazier, W.A., Angeletti, R.H. \& Bradshaw, R.A. Science 176, 482 (1972).

17. Lomedico, P. et al. Cell 18, 545 (1979)

18. Gunning, J. \& Blundell, T. in The Peptides Vol.4 (eds Gross, E. \& Meienhofer, J.) 54 (Academic, New York. 1981).

19. Berger, E.A. \& Shooter, E.M. J. biol. Chem. 253, 804 $(1978)$

20. Isackson, P., Rubin, J.S., Howles, P.N., Gross, K.W. \& Bradshaw, R.A. (submitted).

Mobiey, W.C. et al. N. Engl. J. Med. 297, 1211 (1977).

22. Bell, J. et al. Brain Res. 234, 409 (1982).
19 